\title{
An Application Model of RFID Technology on Progress Measurement and Management of Construction Works
}

\author{
Su-Won Yoon \\ Dept. of Civil, Architectural, \\ and Environmental System \\ Engineering, \\ Sungkyunkwan Univ., \\ Suwon 400-746, S. Korea \\ yoonsuwon@skku.edu
}

\author{
Sangyoon Chin \\ Dept. of Civil, Architectural, \\ and Environmental System \\ Engineering, \\ Sungkyunkwan Univ., \\ Suwon 400-746, S. Korea \\ schin@skku.edu
}

\author{
Yea-Sang Kim \\ Dept. of Civil, Architectural, \\ and Environmental System \\ Engineering, \\ Sungkyunkwan Univ., \\ Suwon 400-746, S. Korea \\ yskim2@skku.ac.kr
}

\author{
Soon-Wook Kwon \\ Dept. of Civil, Architectural, \\ and Environmental System \\ Engineering, \\ Sungkyunkwan Univ., \\ Suwon 400-746, S. Korea \\ swkwon@skku.edu
}

\begin{abstract}
Accurate progress management is one of the critical factors for successful project management in the sense that it enables forecasting risks and taking corrective action by monitoring project status. However, the existing progress measurement methods have limits on accuracy and reliability due to ad-hoc measurement based on the personal experience of the project manager; there are no general standards.

Radio Frequency Identification (RFID) has emerged as a technology that can be effectively applied for real time measurement of project information in the construction industry, such as for labor management, safety management, equipment management, and progress management of various works. However, previous research projects lack considerations for comprehensive management methods of various work types that are closely related to each other since the existing RFID applications have been proposed to manage single work types or single objects.

Therefore, the objective of this research is to propose an application model that can be used to derive an RFID application method by reflecting the characteristics of various works and their integration methods to manage the overall project progress.
\end{abstract}

Keywords: Progress Management, RFID, Application Model

\section{INTRODUCTION}

Accurate progress management is one of the critical factors for successful project management in that it enables management to forecast risks and to take a corrective action by monitoring project status.

Various progress measurement and management methods were proposed for solving this problem in previous studies (Thomas and Mathews 1996, CII 1987, Fleming and Kopplemna 1996 etc.). However, the existing progress measurement methods have limits on accuracy and reliability due to ad-hoc measurements based on the personal experience of the project manager, as there are no general standards. In most construction projects, measurement methods are used inconsistently project by project without objective criteria, which make it more difficult to accumulate and reuse invaluable as-built information (Chin 2004).

Meanwhile, Radio Frequency Identification (RFID) has emerged as a technology that can be effectively applied for real time measurement of project information in the construction industry, such as for labor management, safety management, equipment management, and progress management of various works including concrete, pipe spools, earthwork, structural steel works, and curtain walls. Furthermore, it is expected that RFID will improve the limits on progress management (Jaselskis 1995, CII 2000, Jaselski 2003, Yagi 2005, Song 2005, Goodrum 2005, Chin
2005).

However, previous research projects lack considerations for comprehensive management methods of various work types that are closely related to each other since the existing RFID applications have been proposed to manage single work types or single objects.

Although the existing RFID application model proposed by Jaselskis (2003) provides a flow chart to determine the most appropriate RFID system based on the technological characteristics, it does not consider how to integrate various application methods of RFID in construction to manage the overall project progress.

Therefore, the objective of this research is to propose an application model that can be used to derive an RFID application method by reflecting the characteristics of various works and their integration methods to manage the overall project progress.

\section{LIMITATIONS OF RFID APPLICATION IN CONSTRUCTION}

Radio Frequency IDentification (RFID) is increasingly adapted to manage material, product flow, and progress in the construction industry, such as for concrete, pipe spools, earthwork, structural steel works, curtain walls, etc. (Jaselskis 1995, CII 2000, Jaselskis 2003, Yagi 2005, Song 2005, Goodrum 2005, Chin 2005). Such RFID research has been based on data (identification, time, location, and status 
when sensing measurement target) collected utilizing RFID technology. Thus, RFID can be applied to progress management and measurement for collecting the required data.

However, previous research regarding RFID applications in construction has mainly focused on the feasibility of RFID technology itself for only one work process rather than the characteristics of each work type and the requirements for the overall project progress management under an integrated RFID environment.

Therefore, this research is focused on proposing an application model to derive an RFID application method by reflecting the characteristics of various works and overall project progress.

\section{PROGRESS MEASUREMENT \& MANAGEMENT IN CONSTRUCTION WORKS}

Regarding previous research on progress management, Thomas and Mathews (1996) classified progress management into three categories by the progress measurement method: estimated percent complete, physical progress measurement, and earned value. CII (1987) and Flemming and Koppleman (1996) proposed measurement methods at a more detailed level and suggested the use of a different method based on characteristics of the work item or project (CII - unit completed, incremental milestone, start/finish, supervisor, opinion, cost ratio, and weighted or equivalent units; Fleming \& Koppleman - weighted milestones, fixed formula by task, percent complete and milestones gates, earned standards, apportioned relationships to discrete work, and level of effort).

Although the previous research proposed various measurement and management methods for construction progress, the existing progress measurement methods have limits on accuracy and reliability due to non-existent objective criteria.

Therefore the progress management in this paper is based on measuring and analyzing the degree of progress based on the major quantity selected among work quantity, such as its material, its labor, its machine, or a combination of these.

\section{ANALYSIS ON WORKS FOR DERIVING CONSIDERATION FACTORS}

This study analyzes works for deriving consideration factors to manage and to measure progress using RFID technology. Analysis on the works of this paper using PML (Progress Management Level) is defined as appropriate management level for progress management and measurement using the concept of PMU (Progress Measurement Unit) proposed by Chin (2004), and herein are analyzed approximately 120 work types which are considered as PML in 5 office projects performed previously.

Analysis on works includes the survey of the progress management method, the extract of considerable major items as progress measurement targets, and the analysis of the process. Also, decision making factors for RFID based progress were proposed through this analysis.

\subsection{Progress Management Method}

In the analyzed projects and progress management has been performed by using various methods considering characteristics of management level or work. These various methods (checking completion of work; measuring the quantities of installed items; estimated percent of completion judged by manager based on his subjective experience, etc.) were applied to progress management and measurement based on the importance of the work or the manager's convenience.

As a consequence, the previous project management has a limit that it can not monitor the process of work as is progresses but can only check the finished outcome. However, management methods using RFID offer the benefit that they can monitor process progress and can combine progress management with procurement management, logistics management, lift-up management, etc.

Therefore this study proposes progress management based on monitoring target- attached RFID tags and next the section describes their progress measurement.

\subsection{Progress Measurement Target}

As previously indicated, the progress measurement target is a substance attached RFID tag such as a curtain wall unit, a structural steel component, etc. But from the results of analysis on previously performed projects it appears that merely about $60 \%$ of works can be managed using attached RFID.

Therefore, RFID application methods are considered for works for which it is difficult to attach RFID tags. In the case of finish work, such as waterproofing, after defining a management unit as well as a component being constructed in the building, it may be better to check the change of its status using RFID than to check the process of materials. Another alternative is that progress management could be executed by checking quantities of tags attached to labors that are allocated by a management unit. But since the proposed RFID-based progress management is sufficiently investigated from an efficiency point of view, judgment is needed as to where the existing framework for the proposed progress management is required.

In addition, existing progress management methods have been executed by tracking measurement targets of several types, such as wall as units (curtain wall, PC, structural steel component, etc.), means of transportation (ready-mix concrete etc.), and packing units like pallets (bricks, etc.).

\subsection{Process}

Progress management and measurement utilizing RFID has a merit that it can not only be used to assess performed quantities, but also to monitor process progress and can combine progress management with procurement management, logistics management, lift-up management etc. For this reason, this study analyzed the process of app- 


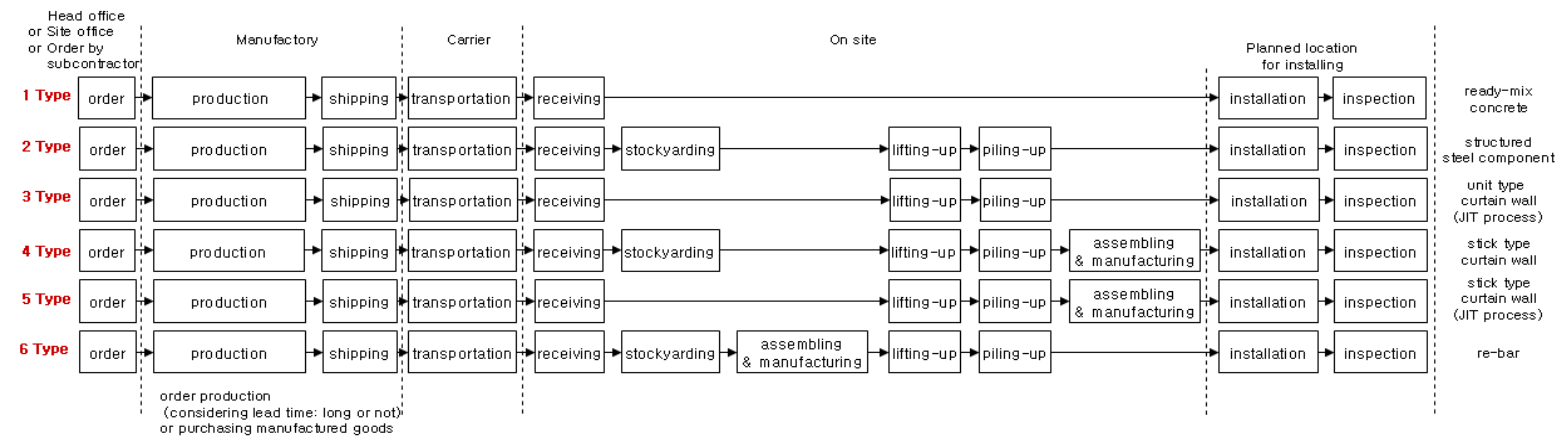

Figure 1. Process type of production in construction project

roximately 120 work types for enlargement combined of management methods. Figure 1 depicts graphically the result of analysis. As illustrated in Fig 1, the process of material flow and production in a construction project may be defined by 6 types. Furthermore, individual steps of defined processes are considered as measurement or management steps.

\section{APPLICATION MODEL}

\subsection{Description of Application Model}

Fig. 2 illustrates the process model for deriving the RFID application method using the result of analysis on works for progress management and measurement based on RFID. The proposed process model in this paper consists of the 6 steps in depicted Fig 2, which are defined together with the proposed consideration factors as follows:

* Step 1 - The objective of Step 1 is to generate a framework for progress management. In this step, PML for progress management and measurement must be generated including a hierarchy for aggregating the progress rates measured.

* Step 2 - Step 2 is proposed for deriving measurement targets, measurement steps, and consideration factors (the distance of sensing, the environments when sensing, whether or not any impediment to sensing exists, whether the target's surface is made of metal or not, location of the attached tag, the status of surface attached tags, etc.) for choosing appropriate RFID technology. Decision making factors through the Step 2 are to select PML among generated PMLs in Step 1, to derive a management target, progress management method, and measurement steps among the 6 process type illustrated in Fig 1, and to propose considerable alternatives for measuring targets at each step. * Step 3 - Step 3 selects RFID technologies based on derived measurement targets, measurement steps, and consideration factors through step 2. In addition, a supplementary step that investigates usable RFID technologies (tag type, hosing type of tag, reader type, available frequency, capability, cost, standards, trend in market etc.) in a market is necessary before executing Step 3.

* Step 4 - Step 4 generates a scenario for progress mangement based on RFID. Fig. 3 graphically depicts an example

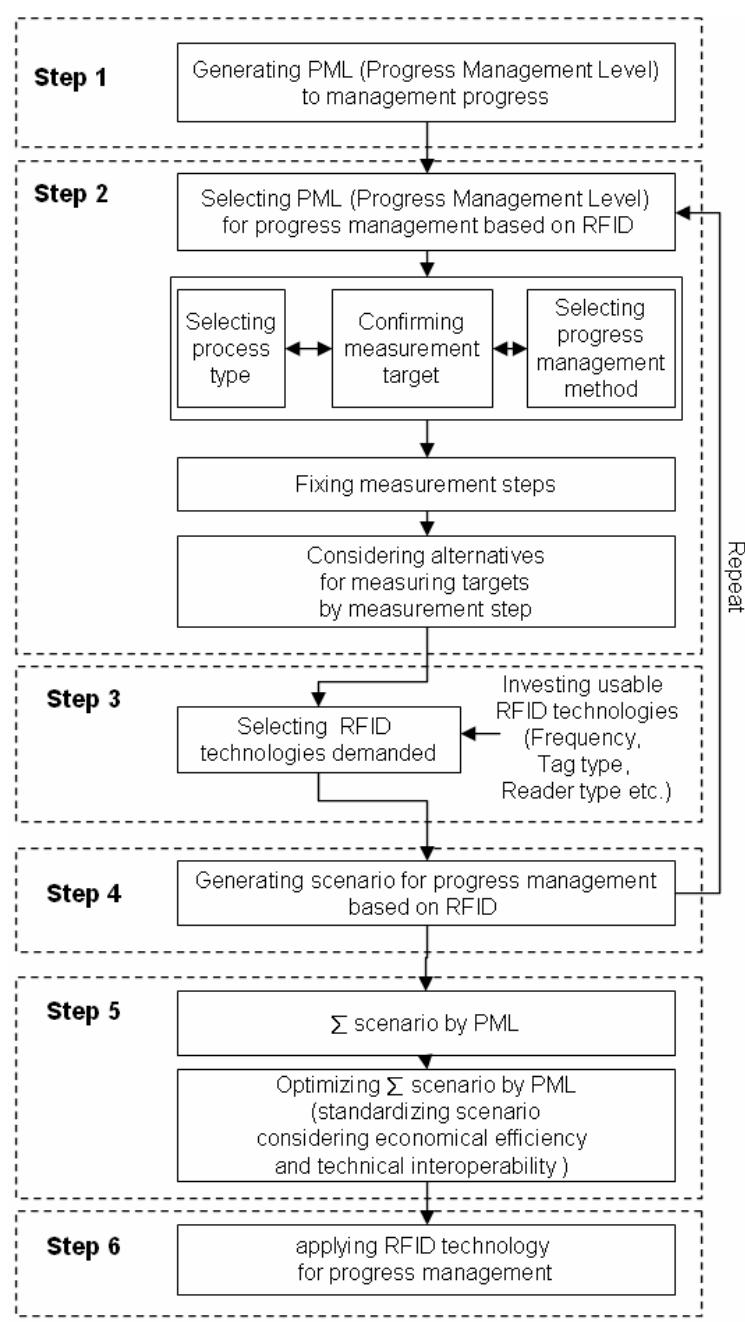

Figure 2. Process Model for Deriving RFID Application Method

of a generated scenario.

* Step 5 - Step 5 synthesizes and optimizes the scenarios derived from repetition of the preceding step. Additionally, when optimizing a scenario, it is important that economical efficiency based on cost of initial investment is considered and the possibility of technical interoperability is reflected. * Step 6 - Step 6 applies RFID technology for progress management and is advanced through several steps as well as designing an information model, developing hardware 
and software, etc. Also, it is necessary for considering the strategy for deriving the voluntary participation of subcontract related operation using RFID.

\subsection{Instance of Using Application Model}

This section describes the instance of making a scenario using the application model proposed in this paper.

This paper assumed that the project consists of 10 floors, the portion of budget quantities for structural steel is $8 \%$ of budget quantities of total project, and 1 floor is divided into two zones. The following is the process of making a scenario using the application model:

* Step 1

- Generating 8F-Bzone structural steel as the instance of $P M L$ under the environment assumed for this instance

* Step 2

- Selecting 8F-Bzone structural steel as PML that can be managed using RFID.

- Selecting type 2 among the proposed 6 types illustrated in Fig. 1.

- Confirming measurement target: structural steel component.

- Selecting weighted milestone among progress methods: planned weight $\rightarrow$ receiving $30 \%$, installation $70 \%$.

- Fixing measurement steps; this consists of 4 steps: manufacture, manufacture inspection, receiving, and installation.

- Selecting an invoice-attached tag as a measurement target of the receiving step.

* Step 3:

- Choosing RFID technology considering the result of Step

2: $13.56 \mathrm{MHz}$, passive type tag, PDA based handheld reader etc.

* Step 4:

- Drawing the scenario illustrated in Fig. 3.

\section{CONCLUSION}

The proposal of this research is to propose an application model that can be used to derive an RFID application method by reflecting the characteristics of various works and their integration methods to manage the overall project progress.

To do so, this research analyzed approximately 120 work types in 5 office projects performed previously, surveyed progress management methods, extracted major items as progress measurement targets, and analyzed the process. Also, an application model consisting of 6 steps and consideration factors by steps is proposed.

This paper is part of a study on an integrated framework for logistics and progress management for construction projects utilizing RFID technology, and is developing more scenarios of various work types and combination methods. At the time of presentation of this paper, more scenarios and combination cases will be shared.

\section{REFERENCES}

[1] Edward J. Jaselskis, Tarek EI-Misalami (2003), "Implementing Radio Frequency Identification in the Construction Process," Journal of Construction Engineering and Management, ASCE, 129(6).

[2] Construction Industry Institute (2000), "Radio Frequency Identification Tagging: Applications for the Construction Industry,” Research Report.

[3] Jongchul Song, Carl T. Hass, Carlos Caldas, Esin Ergen, Burcu Akinci (2005), "Automating the task of tracking the delivery and receipt of fabricated pipe spools in industrial projects," Automation in Construction.

[4] Paul M. Goodrum, Matt A. McLaren, Adam Durfee (2005), "The application of active radio frequency identification technology for tool tracking on construction job sites," Automation in Construction.

[5] Edward J. Jaselskis, Mary Rose Anderson, Charles T. Jahren, Yvan Rodriguez, Steven Njos (1995) "Radio-Frequency Identification Application in

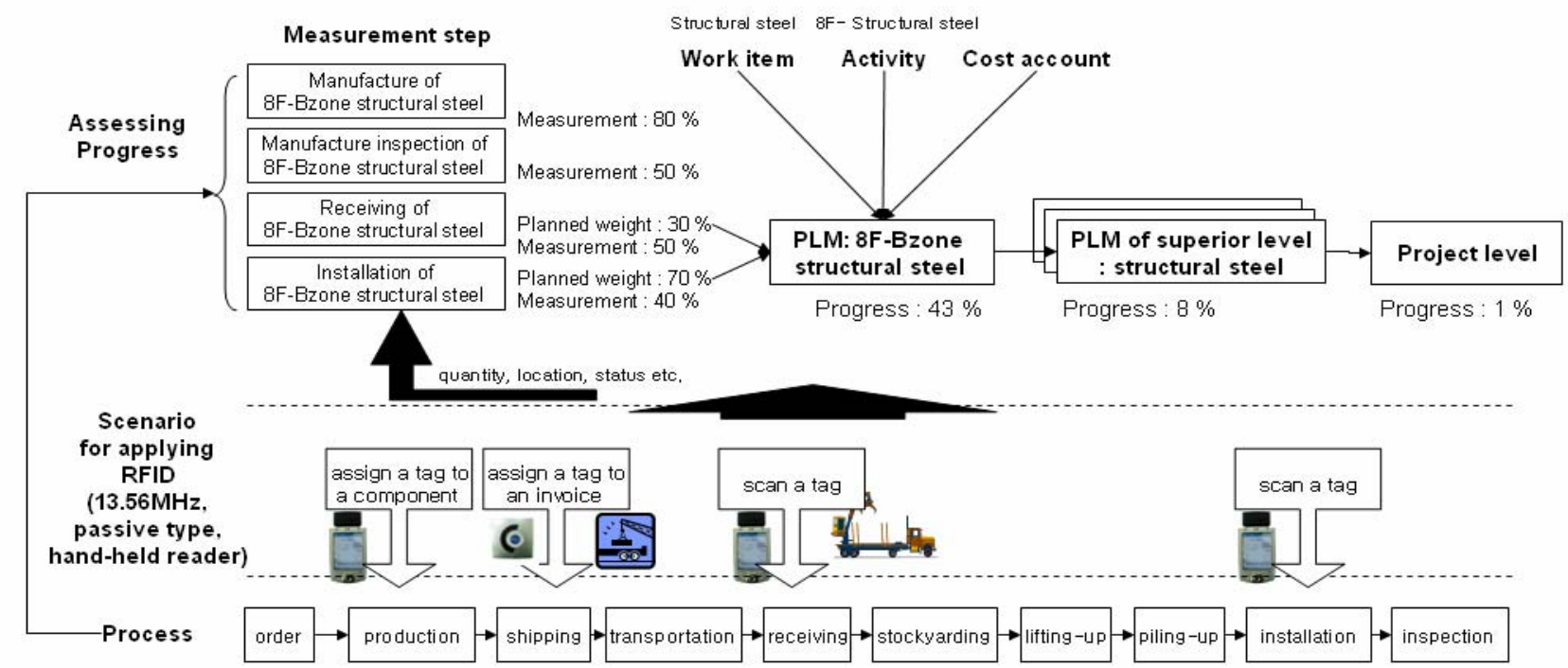

Figure 3. Example of scenario - structural steel 
construction Industry," Journal of Construction Engineering and Management, ASCE, 121(2), pp. 189-196. [6] Sangyoon Chin, Su-Won Yoon , Yea-Sang Kim , Jeongwon Ryu, Cheolho Choi, Chang-Yon Cho (2005), "Realtime 4D CAD + RFID for Project Progress Management," Proceedings of Construction Research Congress, San Diego, California, USA.

[7] Sangyoon Chin, Su-Won Yoon, Yea-Sang Kim, Young -soo Jung, Soon-Chan Park, and Moonhun Chung (2004),

"A Project Progress Measurement and Management System,” Proceedings of International Symposium on Automation and Robotics in Construction, Jeju, S. Korea. [8] Junichi Yagi, Eiji Arai, Tatsuo Arai (2005), "Part and packets unification radio frequency identification application for construction," Automation in Construction 14, pp. 477-490. 